\title{
Percutaneous renal biopsy specimens in stone formers
}

\author{
D J HARRISON,* J A INGLIS, D A TOLLEY \\ From the *Department of Pathology, University of Edinburgh Medical School, and the Department of Urology, \\ Royal Infirmary of Edinburgh, Edinburgh, Scotland
}

SUMMARY A series of renal biopsy specimens taken at the time of percutaneous nephrolithotomy were investigated for the presence and location of foci of microcalcification. Calcium was found in 18 of $25(72 \%)$ of biopsy specimens from stone formers and in only seven of $30(23 \%)$ of control biopsy specimens. This may indicate defective intrarenal handling of calcium as plasma calcium concentration was normal and $40 \%$ had a raised 24 hour urinary calcium excretion.

The widespread use of percutaneous nephrolithotom $y^{1-3}$ has provided a novel avenue for the investigation of renal calculus formation by permitting renal biopsy specimens to be taken and histopathological study of renal parenchyma before the development of endstage scarring. Most work in recent years has relied on approaches aimed at the elucidation of biochemical and pathophysiological mechanisms. ${ }^{45}$ Earlier workers made extensive use of animal models to investigate the renal changes in states of induced hypercalcaemia, hyperparathyroidism, and hypervitaminosis $\mathrm{D} .^{6-8}$ In this preliminary study we report the appearances in renal biopsy specimens of patients presenting for the first time with urinary calculi, placing particular emphasis on the detection and distribution of microdeposits of calcium within the renal parenchyma.

\section{Material and methods}

Twenty five patients were included in the study. Percutaneous renal biopsy was performed under direct vision using cupped forceps after routine one stage percutaneous nephrolithotomy (PCN). All patients had estimations of plasma calcium, phosphate, and urate concentrations; 24 hour urinary excretion of calcium and phosphate; and most had estimation of 24 hour excretion of uric acid three months after PCN.

Renal biopsy specimens for routine light microscopy were fixed in $10 \%$ buffered formalin and embedded in paraffin wax. If indicated, immunoperoxidase staining was performed using methods previously described.' Several cases were examined by electron microscopy using glutaraldehyde fixation and routine processing methods. The presence of calcium was sought by the use of two independent techniques:

Accepted for publication 7 April 1988 the first was Von Kossa silver which substitutes silver for carbonate or phosphate giving a dark brown deposit when positive. While this is not specific for calcium it gives clear histological detail and rarely results in confusing or misleading results. ${ }^{10}$ Specimens were pretreated with saturated lithium carbonate to remove urates which can cause reduction of silver nitrate to metallic silver. The second technique was alizarin red which dissolves calcium deposits at a critical pH 4.2 to form bright red calcium lakes. " The extent, nature, and distribution of microdeposits were recorded.

The presence of calcium in 30 renal biopsy specimens, either open wedge or percutaneous needle, from patients with a variety of conditions, including acute tubular necrosis, hypertension, and glomerulopathies was sought as control data. Multiple tissue samples were taken from two kidneys at necropsy and one nephrectomy specimen removed because of carcinoma.

\section{Results}

The mean (range) of patients' ages was 54 (18-74) years compared with $42(16-66)$ years in the control group. In both groups men predominated. Only one patient had a raised blood urea, presenting with acute renal failure caused by acute tubular necrosis secondary to obstruction by calculus. No patients were hypercalcaemic or hypophosphataemic (mean (SD) calcium $2.37(0 \cdot 10) \mathrm{mmol} / 1$; mean (SD) phosphate 1.00 $(0.23) \mathrm{mmol} / \mathrm{l})$, and in only seven of $18(40 \%)$ was plasma uric acid concentration slightly raised (mean (SD) $0.34(0.08) \mathrm{mmol} / \mathrm{l})$. No patients had 24 hour excretions of phosphate above the normal ranges for subjects on a free calcium-unrestricted diet but five of $12(40 \%)$ were hypercalciuric (mean (SD) calcium 6.00 (2.94) $\mathrm{mmol} / 24$ hours; mean (SD) phosphate $27 \cdot 8(7 \cdot 5)$ 
$\mathrm{mmol} / 24$ hours), and five of 16 patients (31\%) who had 24 hour urate excretion measured were mildly hyperuricosuric (mean (SD) 4.0 (1.7) mmol/24 hours; normal $<5 \mathrm{mmol}$ ).

Of the 25 patients studied, three were normal; three had chronic interstitial fibrosis; 15 chronic interstitial nephritis; one acute tubular necrosis; three mesangial proliferation and interstitial nephritis. Surgical biopsy specimens contained between two and 50 glomeruli (mean 18) and control specimens contained between six and 62 (mean 20). Four of the 25 surgical and three of the $\mathbf{3 0}$ control biopsy specimens contained only medullary tissue. While some cases were histologically normal most showed a focal chronic interstitial nephritis of variable degree, defined simply as an increase in interstitial cells by subjective assessment. Interstitial fibrosis, determined by assessment of fibrous tissue on an MSB preparation, was present in some biopsy specimens. In some there was patchy tubular atrophy and glomerular hyalinisation, indicating some permanent renal damage. Three cases showed a mild increase in glomerular mesangial matrix and mesangial cells. In one case IgM was detected in mesangial regions. None of these cases, however, had clinically important proteinuria, and the importance of the glomerular changes is unclear.

\section{CALCIUM STAINS}

Small deposits of calcium were identified in $72 \%$ of the stone formers and $23 \%$ of the controls. There were several forms of deposit. The commoner form was small, amorphous, rounded bodies of variable size which were present in tubular lumina, tubular cells, and occasionally in the interstitium. The less common form was of very small round deposits seen within basement membranes, particularly of Bowman's capsules (fig 1). Deposits found in the control biopsy specimens were rare, and in six of seven cases were associated only with medullary collecting tubules. One control case had deposits within a cortical tubule, and in no control biopsy specimen was calcification seen in Bowman's capsule. This contrasted with the surgical biopsy specimens where eight of $21(38 \%)$ cases with cortex present had cortical deposits, and five of 21 $(24 \%)$ also had calcific deposits in Bowman's capsules (table). No calcium was found in any of the tissue from three nephrectomy/necropsy kidneys.

\section{ELECTRON MICROSCOPICAL FINDINGS}

If five cases electron microscopy was performed. This showed no specific ultrastructural features, but in

Table Location of microcalcific deposits seen by Von Kossa and alizarin red staining

\begin{tabular}{llll}
\hline & \multicolumn{1}{c}{ Calcification } \\
\cline { 2 - 4 } & Overall & $\begin{array}{l}\text { Cortical } \\
\text { tubules }\end{array}$ & $\begin{array}{l}\text { Bowman's } \\
\text { capsule }\end{array}$ \\
\hline $\begin{array}{l}\text { Control biopsy } \\
\text { specimens }(\mathrm{n}=30)\end{array}$ & $7 / 30(23 \%)$ & $1 / 27^{*}$ & $0 / 27^{*}$ \\
$\begin{array}{l}\text { Stone former } \\
\text { biopsy specimens } \\
(\mathrm{n}=25)\end{array}$ & $18 / 25(72 \%)$ & $8 / 21^{*}$ & $5 / 21^{*}$ \\
\hline
\end{tabular}

*In three control and four stone former biopsy specimens no cortex was present

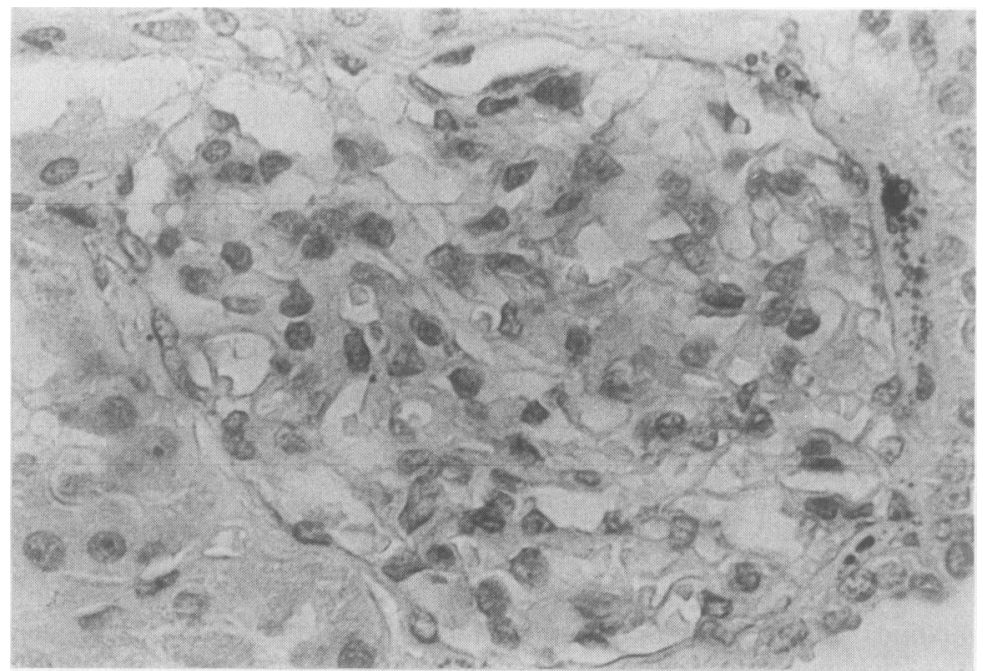

Fig 1 Photomicrograph showing black calcific deposits in basement membrane of Bowman's capsule. (Von Kossa.) 
cases with calcium present small dense bodies were seen in tubular basement membranes (fig 2) and in tubular cell mitochondria (fig 3). These deposits showed no crystalline structure, and although the mitochondrial bodies were seen in some normal biopsy specimens, they were more numerous and slightly larger in the cases with calcium detectable by light microscopy.

\section{Discussion}

In a study of microcalcification in normal necropsy kidneys without the use of special stains, $21 \%$ of kidneys had small foci of calcification, usually around upper collecting tubules in the medulla. ${ }^{12}$ While nephrocalcinosis and nephrolithiasis are distinct entities, there is sometimes an overlap-for example in

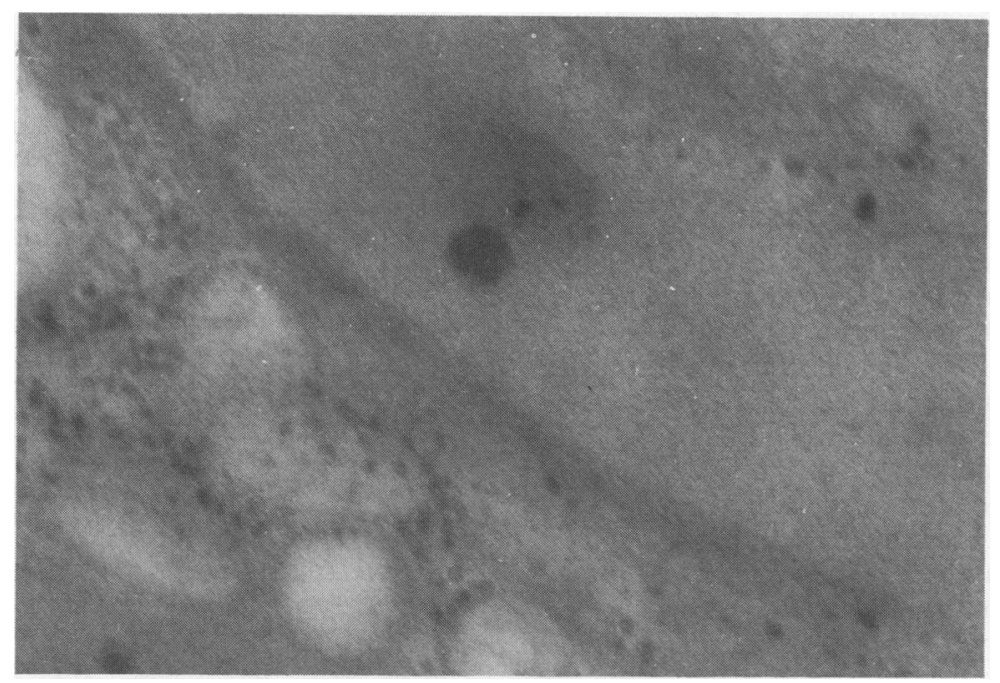

Fig 2 Electron photomicrograph showing small, dense opacity in tubular basement membrane from a stone former.

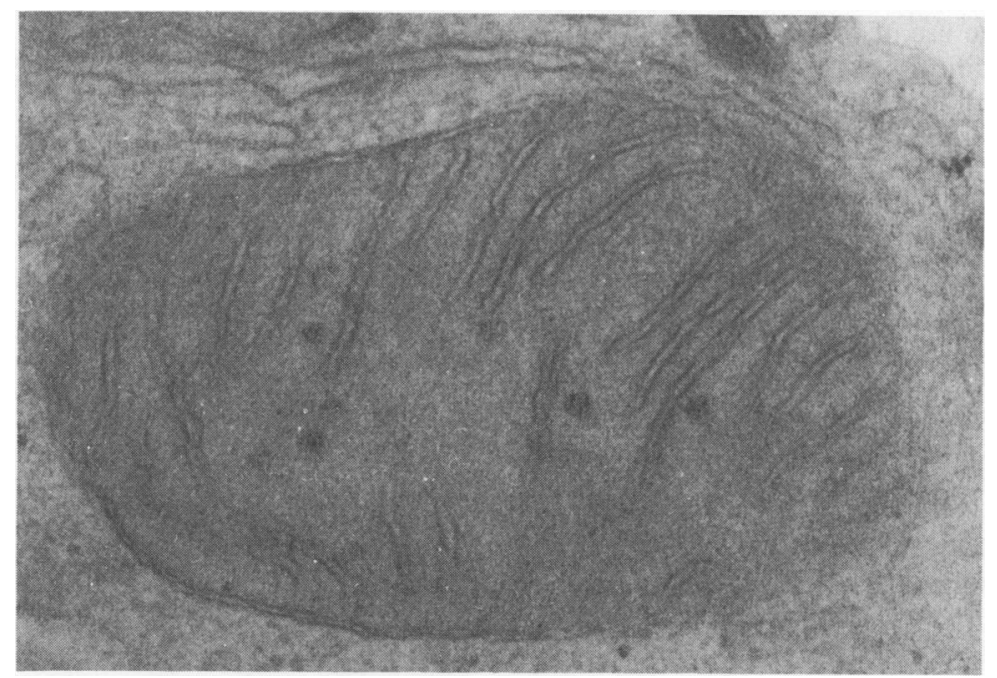

Fig 3 Electron photomicrograph showing dense opacities in mitochondria of a tubular cell from a stone former. 
primary hyperparathyroidism where nephrocalcinosis may accompany nephrolithiasis. ${ }^{8}$ We have found a clear difference between the biopsy specimens from stone formers and those from non-stone formers. This is not explained simply by secondary or dystrophic calcification occurring in an already damaged kidney, as microcalcification was seen in histologically normal biopsy specimens from stone formers and yet absent in inflamed or scarred control renal biopsy specimens. Calcification within Bowman's capsule is seen sometimes in primary hyperparathyroidism, associated with hypercalcaemia and hypercalciuria. As none of our cases had hypercalcaemia detected on a calcium-unrestricted diet, however, underlying hyperparathyroidism seems an unlikely cause for this feature. In a study of paraplegic stone formers it was found that even though the 24 hour excretion of calcium was normal there was a phase of increased calcium phosphate excretion at one time during the period of collection. ${ }^{13}$ We may not have detected some patients with renal hypercalciuria.

The induction of hypervitaminosis $D$ in rats results in stone formation, the first histological change being increased numbers of dense calcific deposits within mitochondria. ${ }^{7}$ Similarly, calcium gluconate and parathyroid hormone have been shown to result in mitochondrial and basement membrane accumulation of calcium. ${ }^{6}$ We have not shown conclusively that the material seen in mitochondria and basement membranes is calcium. We have previously found, however, that routinely processed material for electron microscopy is not ideal for $x$-ray microprobe analysis.' The calcification can be modulated by carbonic anhydrase inhibitors, suggesting that local acidification may be of critical importance. ${ }^{6}$ Therapeutically, the use of bicarbonates and citrates to change renal acidification is of value in some cases,,${ }^{14}$ and thiazides or orthophosphates also have a role. ${ }^{1516}$ The importance of a mildly increased uric acid excretion in some of our patients is unclear, although paraplegic stone formers have been shown to have a higher urate excretion than paraplegic non-stone formers. ${ }^{17}$ The five cases with hyperuricosuria did not show any increase in the incidence or amount of microcalcification in biopsy specimens. In 318 unselected cases of recurrent renal stone formers impaired acidification capacity was found in $19 \%$, with proximal and distal defects equally common. In 28 patients with recurrent calcium nephrolithiasis, 19 of whom had hypercalciuria, nine patients had evidence of defective renal reabsorption of bicarbonate. ${ }^{5}$ These findings strongly suggest the importance of correct acidification and calcium handling in the kidney. It seems likely that the patients we have identified with cortical tubule and Bowman's capsule calcification may show evidence of defective calcium processing by kidney, possibly as a result of acidification defects, and that this may be an indicator of the likely prognosis for those patients, and the need for medical therapeutic intervention. Further studies are in progress.

\section{References}

1 Tolley DA, Buist TAS. The endoscopic management of upper urinary tract stones. Ann Roy Coll Surgs England 1986;68:70-2.

2 Whitfield HN, Mills VA. Percutaneous nephrolithotomy. Br J Urol 1985;57:603-4.

3 Webb DR, Payne SR, Wickham JEA. Extracorporeal shockwave lithotripsy and percutaneous renal surgery. Br J Urol 1986;58: $1-5$.

4 Backman U, Danielson BG, Johansson G, Ljunghall S, Wikstrom B. Incidence and clinical importance of renal tubular defects in recurrent renal stone formers. Nephron 1980;25:96-101.

5 Tessitore N, Ortalda V, Fabris A, et al. Renal acidification defects in patients with recurrent calcium nephrolithiasis. Nephron 1985;41:325-32.

6 Caulfield JP, Schrag PE. Electron microscopic study of renal calcification. Am J Pathol 1964;44:365-81.

7 Scarpelli DG. Experimental nephrocalcinosis: a biochemical and morphologic study. Lab Invest 1965;14:123-41.

8 Heptinstall RH. Calcium and the kidney. In: Pathology of the Kidney Volume 3. Third Edition. Boston: Little, Brown and Company, 1983:1599.

9 Harrison DJ, Thomson D, MacDonald MK. Membranous glomerulonephritis. J Clin Pathol 1986;39:167-71.

10 Pearse AGE. Histochemistry. Volume 2. Third Edition. Edinburgh: Churchill Livingstone, 1972:1405.

11 Pearse AGE. Histochemistry. Volume 2. Third Edition. Edinburgh: Churchill Livingstone, 1972:1135.

12 Pyrah LN, Raper FP. Renal calcification and calculus formation. Br J Urol 1955;333-51.

13 Burr RG, Nuseibeh I. Biochemical studies in paraplegic renal stone patients: I Plasma biochemistry and urinary calcium saturation. Br J Urol 1985;269-74.

14 Preminger GM, Peterson R, Peters PC, Pak CYC. The current role of medical treatment of nephrolithiasis. The impact of improved techniques of stone removal. J Urol 1985;134:6-10.

15 Ljunghall S, Backman U, Danielson BG, Fellstrom B, Johansson G, Wikstrom B. Long term treatment with bendroflumethiazide for prevention in renal stones. In: Smith LH, ed. Urolithiasis: clinical and basic research. New York: Plenum Press, 1981: 241-8.

16 Smith LH, Werness PG, van der Berg CJ, Wilson DM. Orthophosphate treatment in urolithiasis. Scand $J$ Urol Nephrol 1980;53(suppl):253-9.

17 Burr RG, Nuseibeh I, Abiaka CD. Biochemical studies in paraplegic renal stone patients: II Urinary excretion of citrate, inorganic pyrophosphate, silicate and urate. Br J Urol 1985;57:275-8.

Requests for reprints to: Dr D J Harrison, Department of Pathology, University of Edinburgh Medical School, Teviot Place, Edinburgh EH8 9AG, Scotland. 